\title{
Observational evidence for an inside-out substorm onset scenario
}

\author{
M. G. Henderson \\ Los Alamos National Laboratory, Los Alamos, NM, USA \\ Received: 21 October 2008 - Revised: 12 February 2009 - Accepted: 24 March 2009 - Published: 8 May 2009
}

\begin{abstract}
We present observations which provide strong support for a substorm expansion phase onset scenario in which a localized inner magnetospheric instability developed first and was later followed by the development of a Near Earth Neutral Line (NENL) farther down-tail. Specifically, we find that the onset began as a localized brightening of an intensified growth phase arc which developed as a periodic series of arc-aligned (i.e. azimuthally arrayed) bright spots. As the disturbance grew, it evolved into vortical structures that propagated poleward and eventually morphed into an east-west aligned arc system at the poleward edge of the auroral substorm bulge. The evolution of the auroral intensity is consistent with an exponential growth with an e-folding time of around $188 \mathrm{~s}$ (corresponding to a linear growth rate, $\gamma$ of $5.33 \times 10^{-3} \mathrm{~s}^{-1}$ ). During the initial breakup, no obvious distortions of auroral forms to the north were observed. However, during the expansion phase, intensifications of the poleward boundary of the expanding bulge were observed together with the equatorward ejection of auroral streamers into the bulge. A strong particle injection was observed at geosynchronous orbit, but was delayed by several minutes relative to onset. Ground magnetometer data also shows a two phase development of mid-latitude positive H-bays, with a quasi-linear increase in $\mathrm{H}$ between the onset and the injection. We conclude that this event provides strong evidence in favor of the so-called "inside-out" substorm onset scenario in which the near Earth region activates first followed at a later time by the formation of a near-to-mid tail substorm X-line. The ballooning instability is discussed as a likely mechanism for the initial onset.
\end{abstract}

Keywords. Magnetospheric physics (Auroral phenomena; Magnetospheric configuration and dynamics; Storms and substorms)

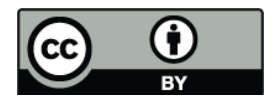

Correspondence to: M. G. Henderson (mghenderson@lanl.gov)

\section{Introduction}

A satisfactory understanding of the physical processes that lead to substorm expansion phase onset and subsequent expansion phase activity has eluded researchers since substorms were first discovered by Akasofu (1964). Numerous models or mechanisms have been introduced over the past 40 years in attempts to explain the observed phenomenology (e.g. Swift, 1967; Hones et al., 1973; Russell and McPherron, 1973; McPherron et al., 1973; Hones, 1977; Lui, 1978; Lui et al., 1988; Roux, 1985; Smith et al., 1986; Rostoker and Eastman, 1987; Kan et al., 1988; Goertz and Smith, 1989; Lui, 1991; Roux et al., 1991; Kan, 1993; Hones and McPherron, 1994; Lyons, 1995; Miura, 2001; Zhu et al., 2007), and while some of these models have been rejected or abandoned over the years, others have been continuously modified and updated. Nevertheless, there is still no clear consensus within the substorm community about which model is most appropriate. Our apparent inability to accept or reject one model over another stems, in part, from the fact that none of the currently viable substorm models has achieved a level of predictive capability sufficient to allow for definitive data-model comparisons. On the other hand, much of the in-situ data that is currently available for such comparisons is also insufficient in terms of spatial distribution and/or temporal resolution. For example, from a purely phenomenological point of view, there is still not even consensus on which parts of the magnetosphere-ionosphere system activates first at substorm onset.

Two key observational constraints that have guided the development of substorm models to date are: (1) That auroral onset (or "auroral breakup") occurs well equatorward of the open-closed boundary on or near the most equatorward discrete arc and that this activity maps fairly close to the Earth (Akasofu, 1977; Kaufmann, 1987; Samson et al., 1992; Murphree et al., 1993; Henderson, 1994; Samson, 1994), and (2) That reconnection and plasmoid releases are typically associated with substorms and that this activity maps

Published by Copernicus Publications on behalf of the European Geosciences Union. 
to more distant regions in the tail. Many of the early substorm models were constructed by implicitly or explicitly ignoring (or at least minimizing the importance of) one or both of these constraints. For example; the "Original" Near Earth Neutral Line (ONENL) model (e.g. see Hones, 1977) violated the first constraint (onset was not as close to the Earth as required); early versions of the Current Disruption (CD) model (e.g. see Lui, 1978, and Lui et al., 1988) and the MIcoupling model of Kan et al. (1988) largely disregarded the second constraint (onset was near-Earth, but X-lines did not play an integral role); the Thermal Catastrophe (TC) model (Smith et al., 1986; Goertz and Smith, 1989) and the Boundary Layer Dynamics (BLD) model (Rostoker and Eastman, 1987), essentially ignored both constraints (both placed onset in the Plasma Sheet Boundary Layer (PSBL) and neither invoked X-line formation). However, since these models were proposed, the general consensus has emerged that a successful substorm model needs to, at least approximately, satisfy both of the observational constraints listed above.

Recognition that the substorm process is associated with both near-Earth and more down-tail regions of activity has played a crucial role in guiding the further development of substorm models. In recent years, two main categories of models have emerged as a result of efforts to satisfy the observational constraints. Lui (1991) proposed a "Synthesis Model" in which the onset first initiates in the near-Earth region due to the growth of an instability there. This initial activity is followed by the tail-ward propagation of a rarefaction wave which destabilizes the more distant thin current sheet region where an $\mathrm{X}$-line forms and a plasmoid is released. This category of model has come to be known as an "inside-out" model because the activity starts close to the Earth and propagates out to the more distant tail. Such models tend to fit ionospheric observations particularly well (e.g. see Friedrich et al., 2001). The ONENL model was also modified in order to produce onset-associated activity much closer to the Earth than where the X-line itself was formed. In this "renovated" NENL model, the substorm Xline forms first in the mid-tail region and drives Bursty Bulk Flows (BBFs) Earthward. The deceleration or "braking" of these flow bursts in the near-Earth region produces the familiar current wedge, Pi2 pulsations and breakup activity on or near the most equatorward arc (Haerendel, 1992; Shiokawa et al., 1997, 1998). This class of model has come to be know as an "outside-in" model because the mid-tail activates first which later induces activity nearer to the Earth. Testing these two classes of models is a major objective of the recently launched THEMIS mission (Donovan et al., 2006).

In this paper, we present detailed observations of a single substorm which provides compelling evidence that the "inside-out" model of substorm development does indeed operate for at least some substorms.

\section{Terminology}

The term "substorm onset" is customarily used to describe the time, $T_{\circ}$, at which the expansion phase of an auroral substorm begins as defined by Akasofu (1964) and we adopt this terminology in the present paper. The expansion phase onset is usually preceded by a "growth phase" period (of variable length) during which time energy is accumulated into the magnetotail. Note that this phase of the substorm was not originally described by Akasofu (1964) but was added later by McPherron (1970).

The "expansion phase" as defined by Akasofu (1964) is divided into three stages (see his Figs. 3-5). The first stage ( $T=T_{\circ}$ to $\approx 5 \mathrm{~min}$ involves a sudden brightening of the southernmost quiet arc and the development of distinct ray structure. The second phase $(T=\approx 5$ to $\approx 10 \mathrm{~min})$ is associated with the development of irregular folds, auroral breakup and rapid motion poleward westward and eastward to form an expanding "substorm bulge". And the third stage $(T=\approx 10$ to $\approx 30 \mathrm{~min}$ ) begins when the bulge in the midnight region reaches its maximum latitude, but expansion continues to the east and west. Note that the "expansion phase onset" begins with the initial rapid brightening of the southernmost arc and is not defined to represent the time at which rapid poleward motion is first observed.

We frequently refer to auroral "arcs" or auroral "arc systems" in the present paper. It is important to note that individual arcs cannot be resolved in the type of global auroral imagery that we present here. Although the arc-like auroral structures that we describe are not resolved, they are likely to be associated with discrete auroral precipitation and may in reality represent multiple closely-separated arcs (hence the term "arc system").

\section{Observations}

In Fig. 1, we present a sequence of IMAGE FUV/WIC images showing the evolution of the northern auroral distribution during a substorm which occurred on 21 November 2002. The images were taken every $2 \mathrm{~min}$ and all images available between 13:58:06 and 14:20:38 UT are shown. The location of substorm onset is highlighted by the yellow arrows in the images taken at 14:00:09 and 14:02:12 UT. Note that since the cadence of the WIC images is $\approx 2 \mathrm{~min}$, we can only say that the auroral onset occurred some time between 14:00:09 and 14:02:12 UT. After onset, the auroral distribution develops in typical substorm manner including expansion in the eastward, westward and poleward directions. By the final image of the sequence, the auroral distribution displays a classic well-formed substorm bulge in the pre-midnight sector. From the first several images of the sequence, we can see that the onset was very clearly located on an intensified "growth phase arc" that was embedded on closed field lines deeply equatorward of the open-closed 


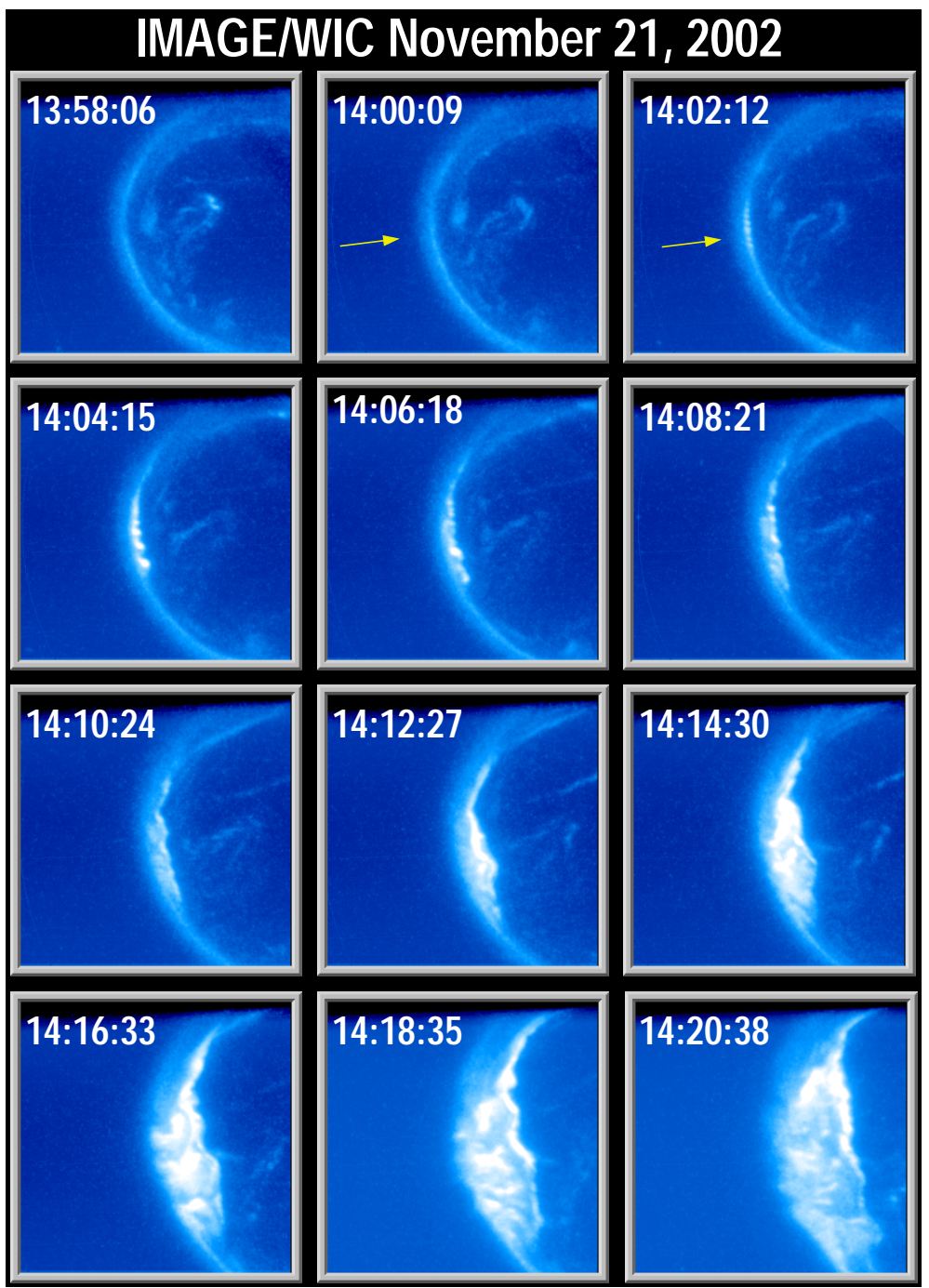

Fig. 1. Sequence of IMAGE FUV/WIC images showing the evolution of the northern auroral distribution during a substorm which occurred on 21 November 2002.

boundary - which must have been situated poleward of the persistent auroral forms seen inside of the nominal oval.

A zoomed-in view of the onset region is presented in Fig. 2. From this more detailed perspective, we can clearly see that the intensified onset region in the 14:02:12 UT image is comprised of a sequence of azimuthally periodic bright spots, and that these bright spots lie precisely on-top of the pre-existing growth phase arc. Such spatially periodic auroral spots have been seen prior to the onset of substorm expansion phase in other studies as well (Henderson, 1994; Elphinstone et al., 1995; Samson et al., 1996; Voronkov et al., $2000,2003)$. In addition, no distortions of the more poleward emissions are evident in the auroral images. By 14:04:15 UT, the periodic bright spots have clearly grown and intensified and have become distorted in the poleward direction. In the image taken at 14:06:18 UT, we can see that the poleward expansion has continued and the forms have begun to distort into an east-west alignment at their poleward edge. By 14:08:21 UT, the poleward expanding distortions have developed into a wavy east-west aligned arc system at the poleward edge of a small bulge-like region.

A continuation of Fig. 2 is presented in Fig. 3. Here we can see that by 14:10:24 UT, the arc has fully formed at the poleward edge of the bulge and that the entire bulge (including the poleward arc) is still fully embedded within the closed field line region. The next four frames show a classic Poleward Boundary Intensification (PBI), followed by the equatorward ejection of streamers into the bulge from the poleward boundary.

In Fig. 4, we present energetic proton data from the Los Alamos National Laboratory (LANL) Synchronous Orbit Particle Analyzers (SOPA) together with the field inclination 


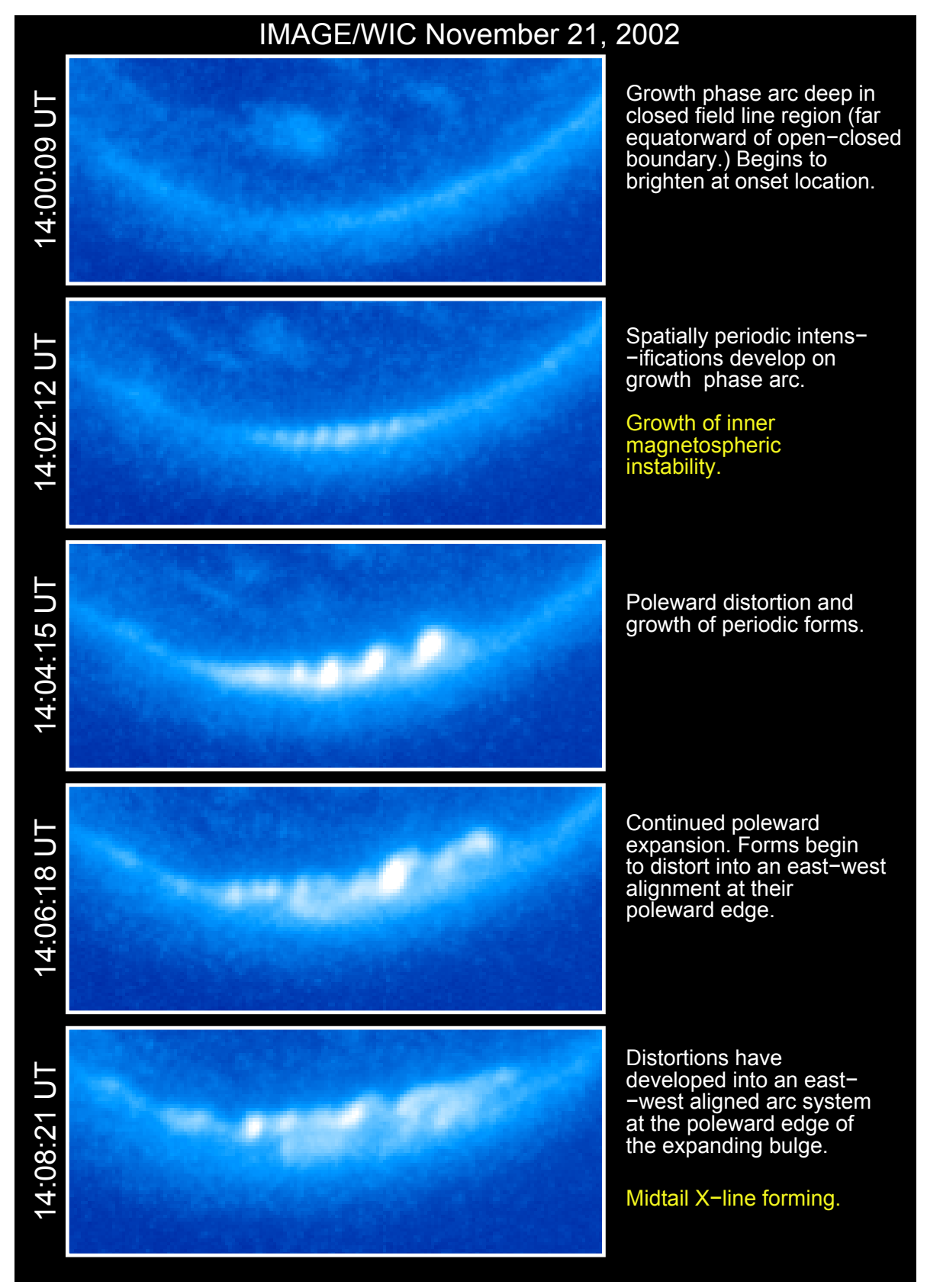

Fig. 2. A close-up view of the onset region. Descriptive comments are given to the right of each image (white text), and an interpretation of the underlying physical cause is given in yellow text.

angles measured at GOES-8 and GOES-10 (bottom panel). Shown in the upper 5 panels are the spin-averaged differential proton fluxes measured at the LANL-01A, LANL-02A, LANL-97A, 1994-084, and 1991-080 spacecraft. The closest satellite to the west of the onset region was LANL-97A and this is where we would expect to see the sharpest and most prompt increase in the protons resulting from a substorm injection. As can be seen in Fig. 4, we do see a sharp flux increase at LANL-97A at 14:11:31 UT (see dashed green vertical line), but it is very interesting to note that this injection was clearly not associated with the initial substorm onset seen in the FUV/WIC images.

The first WIC image that shows the onset-associated brightening was taken at 14:02:09 UT, so the auroral onset occurred sometime between 14:00:09 and 14:02:09 UT. From Fig. 4 this time range clearly does not correspond to any obvious injection feature in the proton data. However, it does correspond extremely well to an abrupt change 


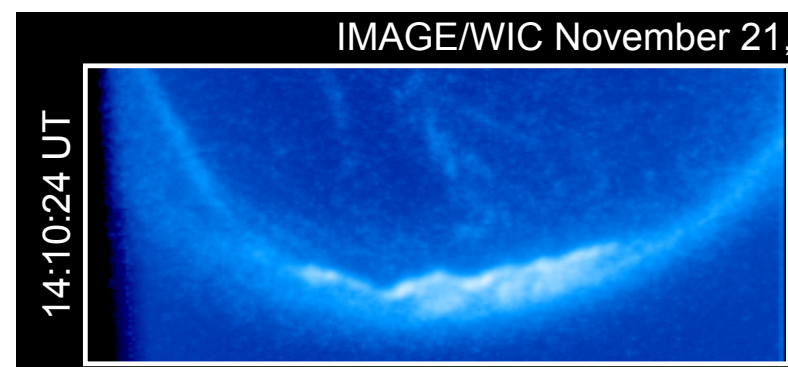

\section{2}

Arc fully formed at

poleward edge of the

bulge. Bulge still

embedded in closed

field-line region.

Midtail X-line fully

formed. Projects to

poleward edge of bulge.

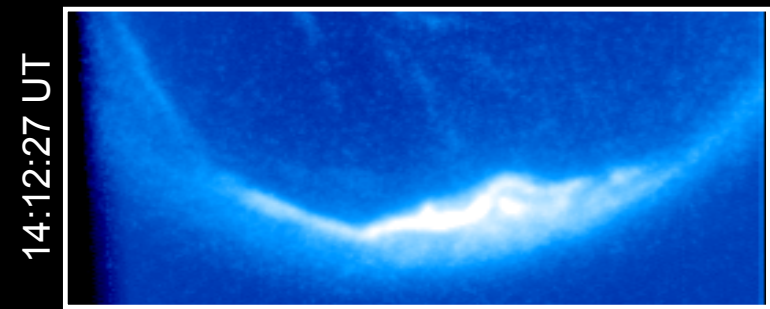

Poleward Boundary Intensification (PBI.)

I.e., arc at poleward

edge intensifies.

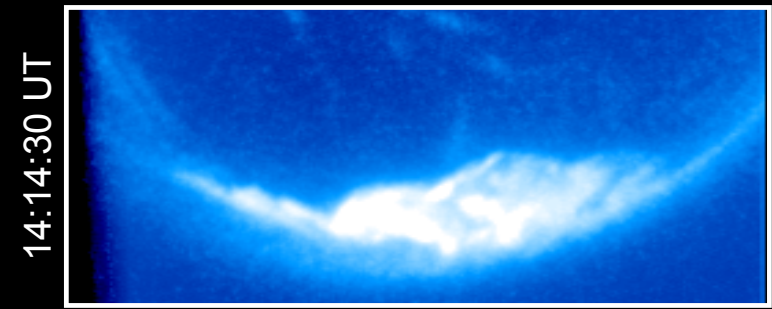

Ejection of streamers

equatorward,

into the bulge.

Earthward directed BBF activity driven by plasma bubbles (localized low

$\mathrm{PV}^{\gamma}$ flux tubes) created at substorm $\mathrm{X}$-line.

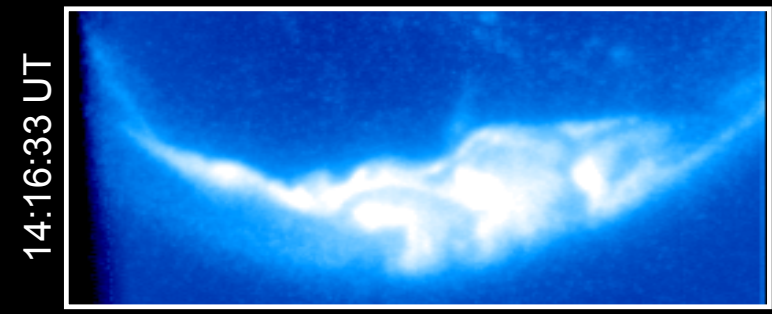

Continued equatorward ejection of streamers from poleward boundary.

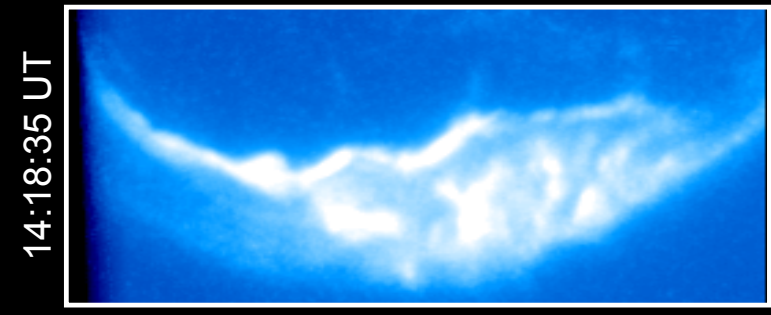

Bulge considerably more expanded. Streamers have evolved into

torches (c.f. Henderson et al., 2002).

Fig. 3. Continuation of Fig. 2. Note that the images shown here are scaled differently than those in Fig. 2.

in the fluxes at 1994-084 at 14:00:21 UT (see dashed orange vertical line). At this time 1994-084 was very close to local magnetic midnight. The slowly decreasing trend in the fluxes between 13:00-14:00 UT are likely due to growth phase stretching of the near-earth field. The stretching causes the spacecraft to be threaded by field lines that map progressively farther down-tail as a function of time - where fluxes are lower. However, near the onset time, the proton fluxes at 1994-084 suddenly stop decreasing and begin to slowly increase instead. The increasing trend continues until a strong injection is seen at 14:11:31 UT. At 1994-084, the change from decreasing fluxes to increasing fluxes at onset likely represents a change from stretching to slow dipolarization of the field there.

In Fig. 5 we show the peak counts within the growth phase arc in the 22.25 and 23.00 MLT meridians. These curves were obtained by first constructing keograms from the sequence of WIC images and then extracting the peak counts over a latitudinal range that includes only the growth phase arc. The auroral onset spanned the 22.25 MLT meridian, and 


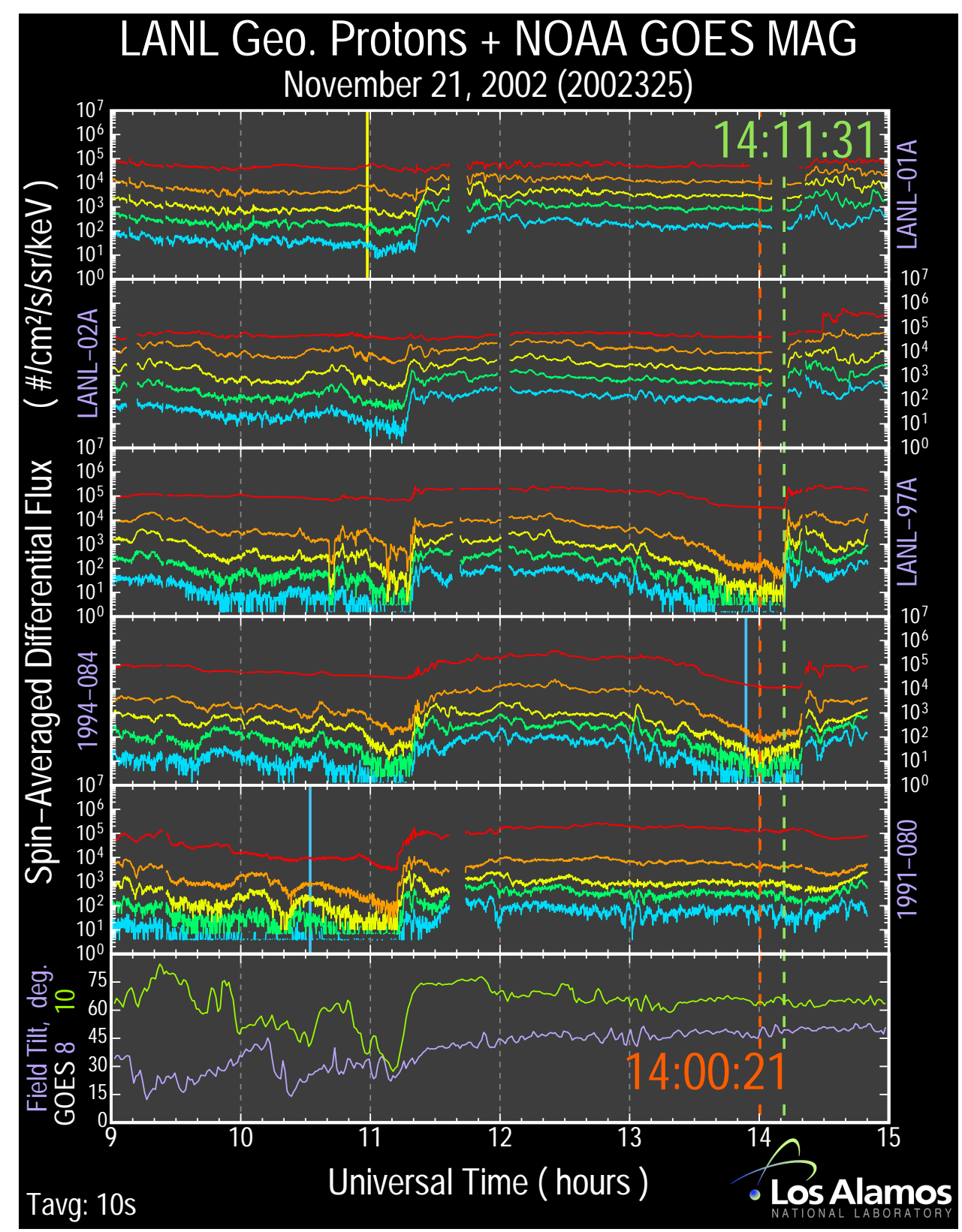

Fig. 4. Energetic proton data from the Los Alamos National Laboratory (LANL) Synchronous Orbit Particle Analyzer (SOPA) instruments. The time at which each satellite crossed local magnetic midnight (noon) is marked with a blue (yellow) line if the crossing occurred in the time range plotted.

within this meridian the auroral intensity clearly shows two distinct intervals of brightening. The first occurred immediately following the 14:00:21 UT time, while the second was associated with the large injection seen at LANL-97A at 14:11:31 UT. In passing, it is also interesting to note that there appears to have been a small but systematic dimming of the aurora during the several minutes prior to onset.

From Fig. 5 it is clear that the auroral luminosity increased very rapidly after 14:00 UT. In Fig. 6 we show a lin- ear fit to $\ln \left(C / C_{\circ}\right)$ versus time for the three images taken at 14:00:09, 14:02:12 and 14:04:15 UT. A linear growth rate of $\gamma=0.0053 \mathrm{~s}^{-1}$ fits the points reasonably well. However, we caution that with only three points separated so widely in time, we cannot definitively conclude that the brightening was associated with a purely linear growth rate. As described by Cowley and Artun (1997), the growth could be have been associated with an even faster "explosive" instability that leads to a "detonation". Unfortunately, the limited temporal 


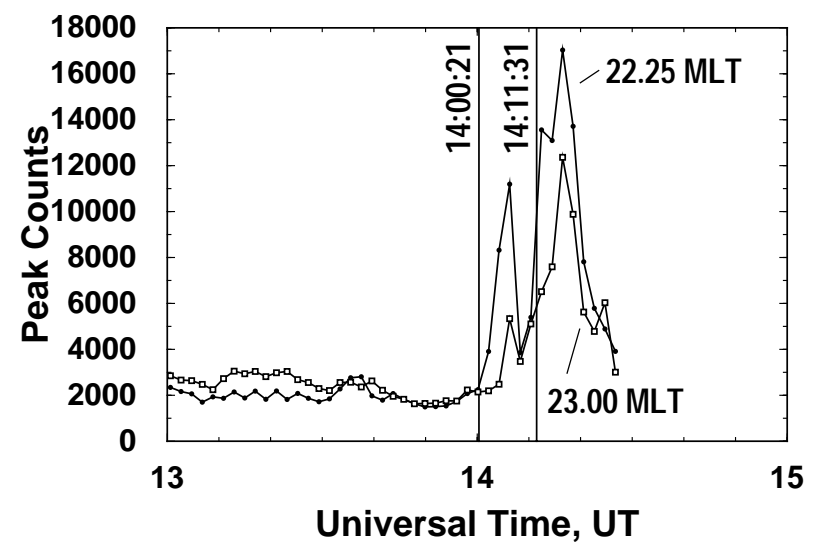

Fig. 5. Peak counts within growth phase arc at 22.25 MLT and 23.00 MLT as a function of time.

resolution of the auroral imagery precludes a more detailed analysis of the growth rate. Nevertheless, from Fig. 6, it appears that the growth rate was at least as fast as linear over the time span of the 3 images used in the fit.

In Fig. 7 we present 1-s resolution H-component and (50$100 \mathrm{~s}$ period) bandpass-filtered $\mathrm{H}$-component traces from the ZYK and TIX stations which are part of the 210MM magnetometer chain (see Table 1 for magnetometer stations used in this study). At onset, these stations were situated equatorward and to the east of the breakup region. As can be seen, the 14:11:31 UT injection time is associated quite well with both a rapid decrease in $\mathrm{H}$ at ZYK as well as the onset of $\mathrm{Pi} 2$ fluctuations there (identified as an increase in power in the 50-100 s bandpass-filtered H-component traces). The ZYK station also shows some $\mathrm{Pi} 2$ activity following the 14:00:21 UT time which is closer to the auroral breakup time.

Data in a similar format from two (Southern Hemisphere) mid-latitude stations (LEM and KAT) are also presented in Fig. 8. The LEM and KAT stations both show positive $\mathrm{H}-$ bays and $\mathrm{Pi} 2$ pulsations, but what is most interesting is the shape of the $\mathrm{H}$-component increases. At both stations, $\mathrm{H}$ began increasing a few minutes prior to 14:00:21 UT and continued increasing in a quasi-linear manner until the time of the major injection at 14:11:31 UT. Weak Pi2 pulsations can be seen at both stations after 14:00:21 UT. However, at 14:11:31 UT, $\mathrm{H}$ began increasing at a much higher rate and this was associated with much stronger $\mathrm{Pi} 2$ pulsations. Note that the strong Pi2 pulsations after 14:11:31 UT can also be seen quite clearly in the raw, un-filtered 1-s H-component traces shown in Fig. 8.

\section{Discussion}

We have presented observations of an auroral substorm which show that the onset first appeared on an intensified growth phase arc well equatorward of the open-closed

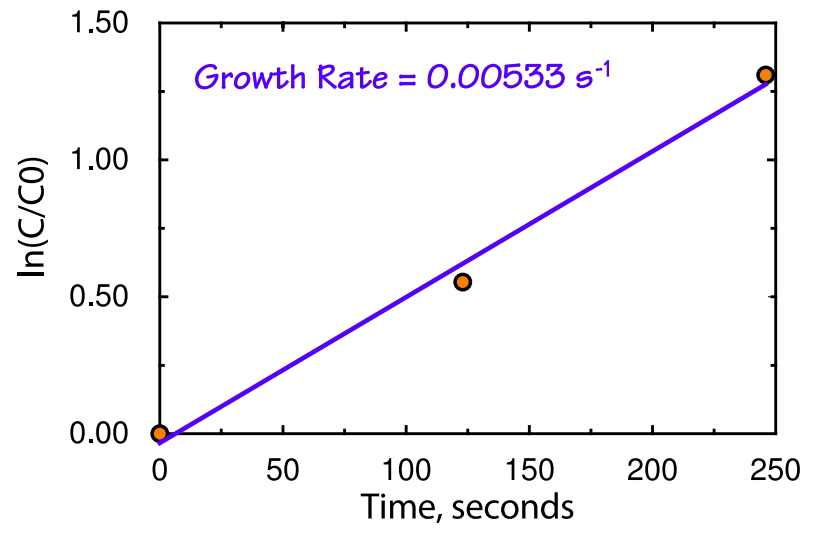

Fig. 6. Linear fit to $\ln \left(C / C_{\circ}\right)$ versus time for the three images taken at 14:00:09, 14:02:12 and 14:04:15 UT. $C$ is the peak count rate in the onset region of the growth phase $\operatorname{arc}\left(C_{\circ}\right.$ is the value of $C$ in the 14:00:09 UT image). The intensity is consistent with a linear growth rate of $\gamma=0.0053 \mathrm{~s}^{-1}$.

Table 1. Selected 210MM magnetometer stations.

\begin{tabular}{cccc}
\hline $\begin{array}{c}\text { Station } \\
\text { Name }\end{array}$ & Code & $\begin{array}{c}\text { Magnetic } \\
\text { Latitude } \\
\text { (deg.) }\end{array}$ & $\begin{array}{c}\text { Magnetic } \\
\text { Longitude } \\
\text { (deg.) }\end{array}$ \\
\hline Tixie Bay & TIX & 65.67 & 196.88 \\
Zyryanka & ZYK & 59.62 & 216.72 \\
Learmonth & LEM & -34.15 & 185.02 \\
Katanning & KAT & -46.63 & 188.24 \\
\hline
\end{tabular}

boundary, and that in the early stages of growth, the breakup developed as a series of azimuthally arrayed bright spots along the growth phase arc. Later, during the expansion phase, poleward boundary intensifications (PBIs) are seen to occur and this activity is associated with the production of auroral streamers within the expanding bulge. A major injection was observed at geosynchronous orbit in association with the substorm, but this occurred several minutes after the first signs of breakup were observed in the aurora. In addition, the mid-latitude ground magnetometer data show positive H-bays comprised of a dual slope increase with the first, more gradual quasi-linear increase following the breakup and a much faster increase following the injection several minutes later.

Since the auroral onset occurred; (1) deep within the closed field line region; (2) developed without any discernable distortions of the auroral emissions on the poleward side of it; and (3) developed in the form of periodic azimuthally arrayed bright spots which evolved into vortical structures that propagated poleward, we are led to the interpretation that the initial breakup during this substorm very likely occurred as a result of the growth of a localized inner magnetospheric instability. (See the yellow text in Figs. 2 and 3.) 


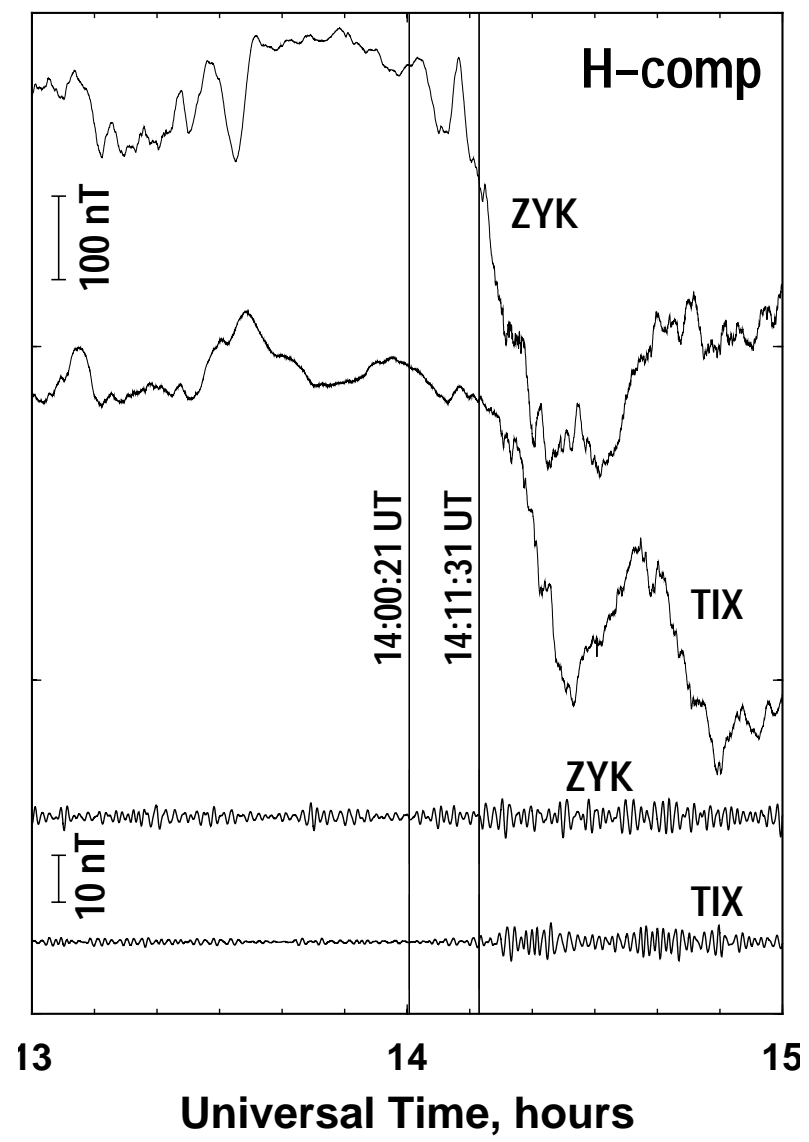

Fig. 7. One-second ground magnetometer data from the ZYK and TIX stations in the $210 \mathrm{MM}$ array.

On the other hand, the auroral activity that occurs during the expansion phase shows that; (1) a bright east-west aligned arc system at the poleward edge of the expanding bulge develops; (2) intensifications of this poleward arc system occur and are associated with; (3) the equatorward ejection of auroral streamers into the bulge. This type of activity is likely to be due to dynamics associated with a newly created substorm X-line in the tail. Bursty and/or localized reconnection across the $\mathrm{X}$-line leads to the production of localized depleted flux tubes (localized tubes of low $P V^{\gamma}$ ) or "bubbles" that rapidly propagate Earthward and produce streamers as an ionospheric signature (e.g. see Chen and Wolf, 1993; Nakamura et al., 1993; Henderson, 1994; Henderson et al., 1994; Henderson et al., 1998; Lyons et al., 1999; Sergeev et al., 1996; Zesta et al., 2000; Nakamura et al., 2005).

With the interpretations given above, we conclude that the onset initially developed as a growth of an instability close to the Earth, and that at some later time a substorm X-line was created. In terms of timing, this scenario is consistent with an "inside-out" onset scenario as proposed by Lui (1991). And, we surmise that the X-line probably formed close to

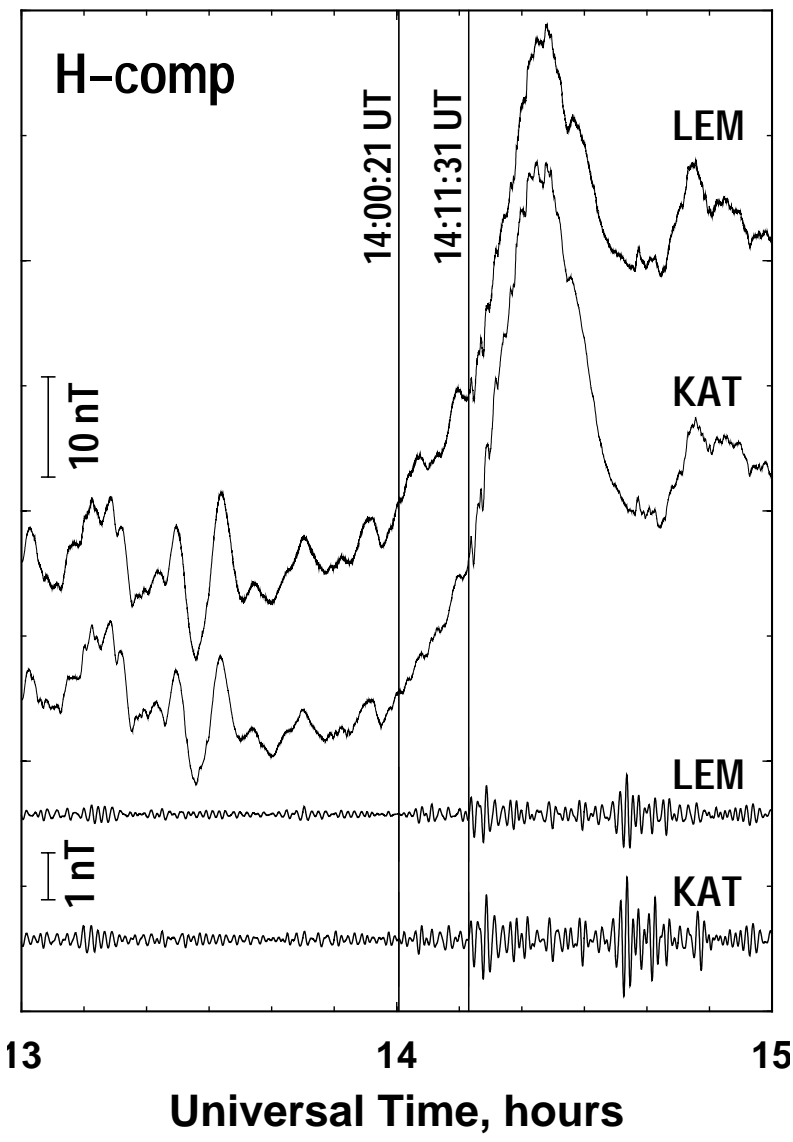

Fig. 8. One-second ground magnetometer data from the LEM and KAT stations in the $210 \mathrm{MM}$ array.

the time at which the east-west aligned arc system developed at the poleward edge of the bulge (close to the images taken at 14:08:21 UT in Fig. 2).

Although this picture is conceptually consistent with the inside-out model of Lui (1991), lack of sufficiently detailed in-situ measurements within the magnetosphere precludes a definitive assessment of exactly what instability may be responsible for the initial auroral breakup. However, that (1) the breakup likely maps close to the Earth near the region separating dipole-like field lines from more stretched tail-like field lines (Samson et al., 1992), (2) the breakup disturbance developed as an azimuthally arrayed series of bright spots that distorted poleward as they grew, and (3) the intensity of the disturbance grew exponentially (with a linear growth rate of $\gamma$ of $5.33 \times 10^{-3} \mathrm{~s}^{-1}$ ) qualitatively points to an instability such as the ballooning instability.

A hypothetical development of the ballooning instability in the inner magnetosphere is shown schematically in Fig. 9 (after Roux et al., 1991). In Fig. 9c, an initial perturbation of the surface separating dipole-like and tail-like field lines in the near-earth magnetotail is shown. Since the $\nabla B$-drift velocity is higher in the tail region than it is in the dipole 
region, charges will begin to accumulate at the boundaries of the wave as shown. The induced perturbation electric field, $\delta E_{\phi}$, will be directed dusk-ward on the tail-ward side of the boundary and dawn-ward on the earthward side. This perturbation electric field will then tend to cause the plasma embedded in the crests and troughs of the wave to $\boldsymbol{E} \times \boldsymbol{B}$ drift earthward and tail-ward respectively, thereby enhancing the initial deformation resulting in a potentially unstable situation. However, whether or not the magnetotail is truly unstable to the ballooning instability depends upon the stabilizing effect of other factors. For example, one must determine what compression/expansion effects occur within plasma elements as they are displaced Earthward or tail-ward in the presence of gradients and curvatures in the magnetic field (e.g. see Ohtani and Tamao, 1992). Just as in the more familiar Rayleigh-Taylor instability, it is entirely possible for a lighter fluid to support a heavier fluid if (for example) upward (downward) displacements of the fluid elements results in sufficiently stabilizing compression (expansion) effects.

Since appropriately detailed in-situ measurements are unavailable for this event, we have no way of quantitatively testing the ballooning instability criteria. However, we speculate that such an instability may well have occurred across a relatively limited azimuthal extent in the onset region of the intensified growth phase arc (between 22:00-23:00 MLT). The negative charge accumulations (blue circles in Fig. 9) would precipitate into the ionosphere to produce upward Field Aligned Currents (FACs) and auroral emissions, while the positive charges would lead to adjacent downward FACs (see Fig. 9a). We therefore expect the instability to produce the type of azimuthally arc-aligned periodic auroral vortical structures that were observed at onset (top panel of Fig. 9b). Further growth of the instability would produce a tail-ward and/or Earthward propagation of the wave crests and troughs until the instability saturated. Precisely this type of behavior can be seen in the 14:04:15 UT image (lower panel of Fig. 9b).

Although much circumstantial evidence points to the ballooning instability as a likely candidate for the substorm onset, a number of outstanding questions remain to be answered: (1) "What triggers the growth of the ballooning instability in the first place", (2) "Why does it go unstable where it does (i.e. across a pre-midnight portion of the growth phase arc)", and; (3) "How does the growth of this instability subsequently lead to the establishment of a midtail X-line?".

Over the past decade, numerous studies have been carried out that are directly relevant to the first two of these questions (see Miura, 2001, and Zhu et al., 2007, for detailed reviews). In general, it is found that the ballooning mode is most unstable in the near-Earth magnetosphere near the region where field lines transition from dipole-like to tail-like in character and that, at times, the criteria for the growth of the instability are likely to be met within the Earth's magnetosphere. In addition, Zhu et al. $(2003,2004,2007)$ find that the bal-

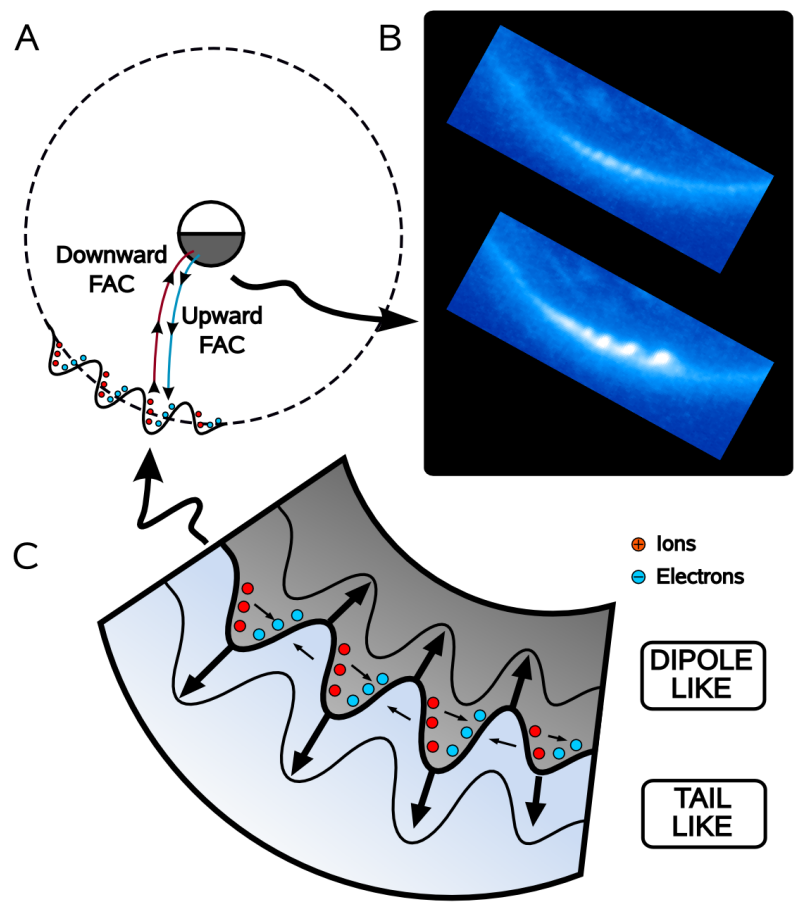

Fig. 9. Schematic representation of the ballooning instability showing the development of an initial perturbation in the surface separating dipole-like and tail-like field lines in the near-earth magnetotail.

looning mode becomes more unstable when the tail current sheet becomes thiner. Thus one way in which the instability could occur is if the tail current sheet thinned beyond a certain instability threshold. This threshold could be crossed spontaneously as the current sheet slowly thinned giving rise to "un-triggered" or "spontaneous" substorms. Or perhaps the threshold could be crossed more impulsively giving rise to "triggered" substorms. For example, Birn et al. (2003) find that magnetotail boundary deformations can lead to the sudden formation of thin current sheets in the tail. Although they implicated this effect as a possible trigger for the onset of instabilities such as collisionless tearing, the lower-hybrid drift instability, ion Weibel or modified two-stream modes, and drift-kink modes, it is possible that it could lead to the growth of the ballooning instability in the near-Earth region as well. Another possibility is that pressure pulses could perturb the magnetospheric pressure profile enough to lead to instability when the inner magnetosphere is already close to the threshold. The time-dependence of the tailward propagating pressure pulse may be important in such a scenario.

It is interesting to note that, while the radial localization of the ballooning instability to the near-Earth region has been reasonably well addressed in the literature, the azimuthal localization of the onset to the pre-midnight region (for typical substorms) is an almost universally ignored aspect of most theoretical studies conducted to date. Indeed this appears to 


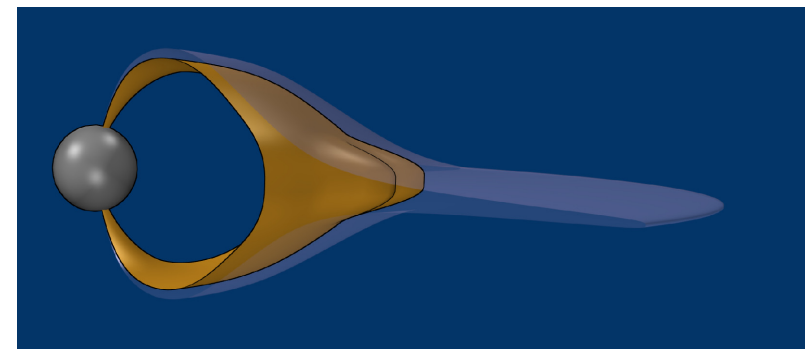

Fig. 10. A 3-D sketch showing how the tailward growth of fingers due to the development of the ballooning instability could protrude into the thin current sheet region. It is possible that such a scenario could lead to the onset of reconnection in the mid-tail region following the initial growth of the ballooning instability closer to the Earth.

be a deficiency in most substorm models, not just those focused on the ballooning instability. Nevertheless, a successful model for substorm onset must be able to explain this important observational characteristic. In terms of the ballooning instability, it is possible that cross-tail pressure gradients or asymmetries in field stretching in the inner magnetosphere could produce a region in the pre-midnight sector that is most susceptible to the growth of the ballooning instability, but much more work needs to be done in order to verify that the ballooning instability not only produces a near-Earth onset but also predicts a pre-midnight onset for typical events.

A possible way in which reconnection could be initiated as a consequence of the growth of the ballooning mode is that the azimuthally periodic fingers characteristic of the instability could grow radially outward into the thin current sheet region that resides in the near-to-mid tail region (see Fig. 10). This may behave like a tail-ward propagating rarefaction wave as hypothesized by Lui (1991), but due to the azimuthal periodicity of the instability, it would also carry considerable cross-tail structure into the thin current sheet region. As suggested by the numerical investigations of Zhu et al. (2007), this may well trigger reconnection in the thin current sheet region. The introduction of azimuthal structure there may naturally lead to cross-tail localization and/or burstiness of reconnection along the NENL. In other words, its possible that the azimuthal periodicity of the initial instability could become "imprinted" into reconnection process to produce locally enhanced reconnection quasi-periodically across the near Earth tail. The locally enhanced reconnection would lead to the copious production of locally depleted flux tubes and these would rapidly propagate Earthward (via interchange) during the expansion phase to produce the auroral streamers observed in the ionosphere.

Although the data presented here strongly supports the inside-out model of substorm development, it is important to stress that since we have presented only a single event study, we cannot generalize this result to all substorms. It may very well be the case that for other events, an outside-in model is more appropriate. This naturally leads us to ask the following two questions: (1) For what fraction of events does the inside-out model operate?; and (2) Does the inside-out model only operate under specific magnetospheric conditions?

Since data available for most substorms are not sufficiently detailed to distinguish between the inside-out versus outsidein models, the first of these questions cannot be answered reliably at this time. However, the second question can be partially addressed. We note that the event examined here is very similar to a handful of events that have been studied in the past. Early examples obtained with the Viking UV imager have been presented (Henderson, 1994; Elphinstone et al., 1995) and more recently, a few cases from ground-based imagers have been reported (Voronkov et al., 2003; Donovan et al., 2006). Two of the clearest substorm onsets showing arc-aligned azimuthally periodic bright spots from the Viking imagery occurred on 24 November 1986 at 10:12:11 UT and on 23 September 1986 at 20:51:46 UT. Both of these cases as well as the event presented here occurred during storm intervals during high $K_{p}$ conditions $\left(K_{p}\right.$ was $6_{\circ}, 5_{-}$, and $5_{-}$, respectively). And in all three of these events, the substorm can be characterized as a so-called "sawtooth substorm" (e.g. see Henderson, 2004; Henderson et al., 2006a,b). On the other hand, the two events reported by Voronkov et al. (2003) and Donovan et al. (2006) occurred under much quieter nonstorm conditions ( $K_{p}$ was $3_{-}$and $3_{\circ}$, respectively). It would therefore appear that these types of onsets can occur under a variety of conditions and are not isolated to storm-time conditions.

\section{Conclusions}

We have presented observations that provide strong evidence that the auroral expansion phase onset was associated with an "inside-out" substorm onset scenario. Specifically, we find that the expansion phase onset began as a rapid brightening of an equatorward growth-phase arc that developed arcaligned spatially periodic bright spots prior to rapid poleward expansion and the development of vortical structures. Such development is completely consistent with Akasofu's original description of expansion phase onset. The evolution of the auroral intensity was consistent with a linear growth rate, $\gamma$ of $5.33 \times 10^{-3} \mathrm{~s}^{-1}$. The ejection of auroral streamers equatorward from an east-west aligned arc system that formed poleward of the original onset region together with the observation that poleward emissions remained undisturbed during the onset argue strongly that a near Earth disturbance developed first followed by the development of a substorm X-line farther downtail. We have also argued that the ballooning instability is a likely cause for the initial inner magnetospheric disturbance and that the substorm X-line could be produced by the outward protrusion of ballooning fingers into a thin current sheet region. The localized (in the cross-tail sense) 
reconnection required to produce the Earthward-penetrating bubbles believed to be responsible for the auroral streamers may result from the azimuthal periodicity of the initial ballooning disturbance.

Acknowledgements. This research was supported at Los Alamos National Laboratory by NSF GEM grant ATM-0202303. The highresolution $1 \mathrm{~s} 210 \mathrm{MM}$ magnetometer data was kindly provided by K. Shiokawa from the Solar-Terrestrial Environment Laboratory Nagoya University.

Topical Editor R. Nakamura thanks M. Liemohn and J. Samson for their help in evaluating this paper.

\section{References}

Akasofu, S. I.: The development of the auroral substorm, Planet. Space Sci., 12, 273-282, 1964.

Akasofu, S. I.: Physics of magnetospheric substorms, D. Reidel, Dordrecht, Netherlands, 1977.

Birn, J., Schindler, K., and Hesse, M.: Formation of thin current sheets in the magnetotail: Effects of propagating boundary deformations, J. Geophys. Res., 108(A9), 1337, doi:10.1029/2002JA009641, 2003.

Chen, C. X. and Wolf, R. A.: Interpretation of high-speed flows in the plasma sheet, J. Geophys. Res., 98, 21409-21419, 1993.

Cowley, S. C. and Artun, M.: Explosive instabilities and detonation in magnetohydrodynamics, Phys. Rep., 283, 185-211, 1997.

Donovan, E., Mende, S., Jackel, B., Frey, H., Syrjasuo, M., Voronkov, I., Trondsen, T., Peticolas, L., Angelopoulos, V., Harris, S., Greffen, M., and Connors, M.: The THEMIS all-sky imaging arraysystem design and initial results from the prototype imager, J. Atmos. Solar Terr. Phys., 68, 1472-1487, 2006.

Elphinstone, R. D., Hearn, D. J., Cogger, L. L., Murphree, J. S., Singer, H., Sergeev, V., Mursula, K., Klumpar, D. M., Reeves, G. D., Johnson, M., Ohtani, S., Potemra, T. A., Sandahl, I., Nielsen, E., Persson, M., Opgenoorth, H., Newell, P. T., and Feldstein, Y. I.: Observations in the vicinity of substorm onset: Implications for the substorm process, J. Geophys. Res., 100, 7937-7969, 1995.

Friedrich, E., Samson, J. C., Voronkov, I., and Rostoker, G.: Dynamics of the substorm expansion phase, J. Geophys. Res., 106, 13145-13163, 2001.

Goertz, C. K. and Smith, R. A.: The thermal catastrophe model of substorms, J. Geophys. Res., 94, 6581-6596, 1989.

Haerendel, G.: Disruption, ballooning, or auroral avalanche - On the cause of substorms, in: Proc. First International Conference on Substorms (ICS-1), edited by: Kan, J. R., Craven, J. D., and Akasofu, S.-I., p. 417, European Space Agency Special Publicaton SP-335, 1992.

Henderson, M. G.: Impications of Viking Imager Results for Substorm Models, PhD Thesis, Department of Physics and Astronomy, University of Calgary, 1994.

Henderson, M. G.: The May 2-3 1986 CDAW-9C interval: A sawtooth event, J. Geophys. Res., 31, L11804, doi:10.1029/2004GL019941, 2004.

Henderson, M. G., Murphree, J. S., and Reeves, G. D.: The activation of the dusk-side and the formation of north-south aligned structures during substorms, in: Proc. Second International Conference on Substorms (ICS-2), edited by: Kan, J. R., Craven,
J. D., and Akasofu, S.-I., p. 37, Geophysical Institute, University of Alaska Fairbanks, 1994.

Henderson, M. G., Reeves, G. D., and Murphree, J. S.: Are northsouth aligned auroral structures an ionospheric manifestation of bursty bulk flows?, Geophys. Res. Lett., 25, 3737-3740, 1998.

Henderson, M. G., Reeves, G. D., Skoug, R., Thomsen, M. F., Denton, M. H., Mende, S. B., Immel, T. J., Brandt, P. C., and Singer, H. J.: Magnetospheric and auroral activity during the April 18, 2002 sawtooth event, J. Geophys. Res., 111, A01S90, doi:10.1029/2005JA011111, 2006a.

Henderson, M. G., Skoug, R., Donovan, E., Thomsen, M. F., Reeves, G. D., Denton, M. H., Singer, H. J., McPherron, R. L., Mende, S. B., Immel, T. J., Sigwarth, J. B., and Frank, L. A.: Substorms during the 10-11 August 2000 sawtooth event, J. Geophys. Res., 111, A06206, doi:10.1029/2005JA011366, 2006 b.

Hones, E. W.: Substorm processes in the magnetotail: comments on 'on hot tenuous plasmas, fireballs, and boundary layers in the earth's magnetotail', J. Geophys. Res., 82, 5633-5643, 1977.

Hones, E. W. and McPherron, R. L.: Evidence supporting the NearEarth Neutral Line Model of Substorms: A Reminder and an update, in: Proc. Second International Conference on Substorms (ICS-2), edited by: Kan, J. R., Craven, J. D., and Akasofu, S.I., p. 167, Geophysical Institute, University of Alaska Fairbanks, 1994.

Hones, E. W., Asbridge, J., Bame, S., and Singer, S.: Substorm variations of the magnetotail plasma sheet from $X_{S M} \approx-6 R_{E}$ to $X_{S M} \approx-60 R_{E}$, J. Geophys. Res., 78, 109-132, 1973.

Kan, J. R.: A global magnetosphere-ionosphere coupling model of substorms, J. Geophys. Res., 98, 17263-17275, 1993.

Kan, J. R., Zhu, L., and Akasofu, S. I.: A theory of substorms: Onset and subsidence, J. Geophys. Res., 93, 5624-5640, 1988.

Kaufmann, R. L.: Substorm currents: growth phase and onset, J. Geophys. Res., 92, 7471-7489, 1987.

Lui, A. T. Y.: Estimates of Current Changes in the Geomagnetotail associated with a substorm, Geophys. Res. Lett., 5, 853-856, 1978.

Lui, A. T. Y.: A synthesis of magnetospheric substorm models, J. Geophys. Res., 96, 1849-1856, 1991.

Lui, A. T. Y., Lopez, R. E., Krimigis, S. M., McEntire, R. W., Zanetti, L. J., and Potemra, T. A.: A case study of magnetotail current sheet disruption and diversion, Geophys. Res. Lett., 15, 721-724, 1988.

Lyons, L. R.: A new theory for magnetospheric substorms, J. Geophys. Res., 100, 19069-19081, 1995.

Lyons, L. R., Nagai, T., Blanchard, G. T., Yamamoto, T., Mukai, T., Nishida, A., Samson, J. C., and Kokobun, S.: Association Between Geotail Plasma Flows and Auroral Separatrix Disturbances, J. Geophys. Res., 104, 4485-4500, 1999.

McPherron, R. L.: Growth phase of magnetospheric substorms, J. Geophys. Res., 75, 5592-5599, 1970.

McPherron, R. L., Russell, C. T., and Aubry, M. P.: Satellite studies of magnetospheric substorms on August 15, 1968, 9. Phenomenological model for substorms, J. Geophys. Res., 78, 31313149, 1973.

Miura, A.: Ballooning instability as a mechanism of the nearEarth onset of substorms, Space Sci. Rev., 195, 387-398, doi:10.1023/A:1005249915285, 2001.

Murphree, J. S., Elphinstone, R. D., Henderson, M. G., Cogger, 
L. L., and Hearn, D. J.: Interpretation of optical substorm onset observations, J. Atmos. Terr. Phys., 55, 1159-1170, 1993.

Nakamura, R., Oguti, T., Yamamoto, T., and Kokobun, S.: Equatorward and poleward expansion of the auroras during substorms, J. Geophys. Res., 98, 5743-5759, 1993.

Nakamura, R., Amm, O., Laakso, H., Draper, N. C., Lester, M., Grocott, A., Klecker, B., McCrea, I. W., Balogh, A., Rème, H., and André, M.: Localized fast flow disturbance observed in the plasma sheet and in the ionosphere, Ann. Geophys., 23, 553-566, 2005, http://www.ann-geophys.net/23/553/2005/.

Ohtani, S. and Tamao, T.: The stability of the near-earth magnetotail against the ballooning instability, in: Proc. of the First International Conf. on Substorms, Kiruna, Sweden, p. 333, 1992.

Rostoker, G. and Eastman, T.: A boundary layer model for magnetospheric substorms, J. of Geophy. Res., 92, 12187-12201, 1987.

Roux, A.: Generation of field-aligned current structures at substorm onset, Eur. Space Agency Spec. Publ., ESA SP-235, 151-159, 1985.

Roux, A., Perraut, S., Robert, P., Morane, A., Pedersen, A., Korth, A., Kremser, G., Aparicio, B., Rodgers, D., and Pellinen, R.: Plasma sheet instability related to the westward travelling surge, J. Geophys. Res., 96, 17697-17714, 1991.

Russell, C. T. and McPherron, R. L.: The magnetotail and substorms, Space Sci. Rev., 15, 205-266, 1973.

Samson, J. C.: Mapping substorm intensifications from the ionosphere to the magnetosphere, in: Proc. Second International Conference on Substorms (ICS-2), edited by: Kan, J. R., Craven, J. D., and Akasofu, S.-I., p. 237, Geophysical Institute, University of Alaska Fairbanks, 1994.

Samson, J. C., Lyons, L. R., Newell, P. T., Creutzberg, F., and Xu, B.: Proton aurora and substorm intensifications, Geophys. Res. Lett., 19, 2167-2170, 1992.

Samson, J. C., Cogger, L. L., and Pao, Q.: Observations of field line resonances, auroral arcs, and auroral vortex structures, J. Geophys. Res., 101, 17373-17383, 1996.

Sergeev, V. A., Angelopoulos, V., Gosling, J. T., Cattell, C. A., and Russell, C. T.: Detection of localized, plasma-depleted flux tubes or bubbles in the midtail plasma sheet, J. Geophys. Res., 101, 10817-10826, 1996.
Shiokawa, K., Baumjohann, W., and Haerendel, G.: Braking of high-speed flows in the near-Earth tail, Geophys. Res. Lett., 10, 1179-1182, 1997.

Shiokawa, K., Baumjohann, W., Haerendel, G., Paschmann, G., Fennell, J. F., Friis Christensen, E., Luhr, H., Reeves, G. D., Russell, C. T., Sutcliffe, P. R., and Takahashi, K.: High-speed flow, substorm current wedge, and multiple Pi 2 pulsations, J. Geophys. Res., 103, 4491-4507, 1998.

Smith, R. A., Goertz, C. K., and Grossmann, W.: Thermal catastrophe in the Plasma Sheet Boundary Layer, Geophys. Res. Lett., 13, 1380-1383, 1986.

Swift, D. W.: The possible relationship between the auroral breakup and the interchange instability of the ring current, Planet. Space Sci., 15, 1225-1237, 1967.

Voronkov, I. O., Donovan, E. F., Jackel, B. J., and Samson, J. C.: Large-scale vortex dynamics in the evening and midnight auroral zone: Observations and simulations, J. Geophys. Res., 105, 18505-18518, 2000.

Voronkov, I. O., Donovan, E. F., and Samson, J. C.: Observations of the phases of the substorm, J. Geophys. Res., 108, 1073, doi:10.1029/2002JA009314, 2003.

Zesta, E., Lyons, L. R., and Donovan, E.: The Auroral Signature of Earthward Flow Bursts Observed in the Magnetotail, Geophys. Res. Lett., 27, 3241-3244, 2000.

Zhu, P., Bhattacharjee, A., and Ma, Z. W.: Hall magnetohydrodynamic ballooning instability in the magnetotail, Phys. Plasmas, 10, 249, doi:10.1063/1.1526830, 2003.

Zhu, P., Bhattacharjee, A., and Ma, Z. W.: Finite ky ballooning instability in the near-Earth magnetotail, J. Geophys. Res., 109, A1121, doi:10.1029/2004JA010505, 2004.

Zhu, P., Sovinec, C. R., Hegna, C. C., Bhattacharjee, A., Germaschewski, K., and Miura, A.: Nonlinear ballooning instability in the near-Earth magnetotail: Growth, structure, and possible role in substorms, J. Geophys. Res., 112, A06222, doi:10.1029/2006JA011991, 2007. 